01;03

\title{
Стабильность заряженных нанопузырей в воде
}

\author{
(ㄷ С.И. Кошоридзе, Ю.К. Левин
}

Институт прикладной механики РАН, Москва, Россия

ฯ E-mail: iam-ras@mail.ru

\section{Поступило в Редакцию 10 сентября 2018 г.}

Показано, что экспериментально обнаруженные наноразмерные пузыри в водной среде возникают самопроизвольно за счет минимизации энергии Гиббса газожидкостной дисперсной системы. Повышенное давление газа внутри нанопузыря постепенно выравнивается (по закону Генри) с атмосферным давлением воздуха, растворенного в воде. Радиус пузыря несколько уменьшается, и пузырь переходит в устойчивое состояние.

DOI: 10.21883/PJTF.2019.01.47161.17521

Экспериментально обнаружено, что водная среда содержит поглощенный газ не только в виде отдельных молекул, но и в виде нанопузырей (НП). Было высказано предположение $[1,2]$, что стабильность пузырей определена их электрическим зарядом $q$. Задачей настоящей работы является теоретическое обоснование наблюдаемого эффекта путем исследования энергии Гиббса $G$ системы вода-НП. Наличие минимума служит основанием возможности гомогенной генерации и устойчивости НП в водной среде. Такие нанопузыри с минимальной энергией Гиббса назовем стационарными. В работе [3] были рассмотрены пузыри с внутренним давлением $p_{0}=1 \mathrm{~atm}$, где молекулы воздуха в газообразной и растворенной в воде фазах (по закону Генри) находятся в равновесии. Эти нанопузыри назовем равновесными. Стационарные пузыри имеют наибольшую вероятность гомогенной генерации, а равновесные возможность постоянно существовать в окружающей их водной среде. Дополним правую часть известного уравнения для энергии Гиббса системы вода-НП [4] третьим - электростатическим - слагаемым:

$$
\begin{gathered}
G=-(4 / 3) \pi r^{3} \Delta p+4 \pi r^{2} \alpha+q^{2} / 2 C, \\
\Delta p=p-p_{0}=2 \alpha / r-q^{2} / 32 \pi^{2} \varepsilon \varepsilon_{0} r^{4}
\end{gathered}
$$

- разность давлений внутри пузырька $p$ и воды $p_{0}$, которая определена исходя из уравнения для баланса давлений НП [1-3]: сжатие поверхностным натяжением уравновешено расширяющим давлением взаимодействия зарядов на поверхности НП.

Обычно давление $p_{0}$ равно атмосферному; $\alpha=$ $=0.072 \mathrm{~J} / \mathrm{m}^{2}-$ коэффициент поверхностного натяжения на границе вода-пузырь; $C=4 \pi \varepsilon_{0} \varepsilon r\left(r+L_{D}\right) / L_{D}-$ электрическая емкость нанопузыря, представляемого как сферический конденсатор с расстоянием между обкладками, равным длине Дебая $L_{D}=\sqrt{\varepsilon \varepsilon_{0} k_{\mathrm{B}} T / 2 z^{2} e^{2} N_{A} c} ; c-$ мольная концентрация растворенной соли. Электрическая постоянная $\varepsilon_{0}$, диэлектрическая проницаемость воды $\varepsilon=81, T-$ абсолютная температура, $e, k_{\mathrm{B}}, N_{A}, z$ - элементарный заряд, постоянная Больцмана, число Авогадро и степень ионизации иона в симметричном электролите, соответственно. Подставляя (2) в (1), получим

$$
G=-1.33 \pi r^{3}\left(2 \alpha / r-q^{2} / 32 \pi^{2} \varepsilon \varepsilon_{0} r^{4}\right)+4 \pi r^{2} \alpha+q^{2} / 2 C .
$$

На рис. 1 показана зависимость энергии Гиббса $G$ образования заряженного нанопузырька от его радиуса $r$ при $q=10^{-15} \mathrm{C}$. Аналогичные зависимости получены в диапазоне зарядов $q=10^{-17}-10^{-13} \mathrm{C}$ при значениях радиуса $r=2-1000 \mathrm{~nm}$. Это указывает на возможность самопроизвольного формирования нанопузырей в водной среде.

Для определения характеристик стационарного НП, приравнивая производную энергии Гиббса (3) к нулю: $d G(r) / d r=0$, находим зависимость заряда $q_{s t}$ стационарного НП от его радиуса

$$
q_{s t}(r)=\sqrt{64 \pi^{2} \alpha \varepsilon \varepsilon_{0} r^{3}\left(1+3 L_{D}\left(2 r+L_{D}\right) /\left(r+L_{D}\right)^{2}\right)} .
$$

Отметим, что $q_{s t}(r)$ отличается от ранее найденной зависимости $q_{e q}(r)$ для равновесного НП [2]:

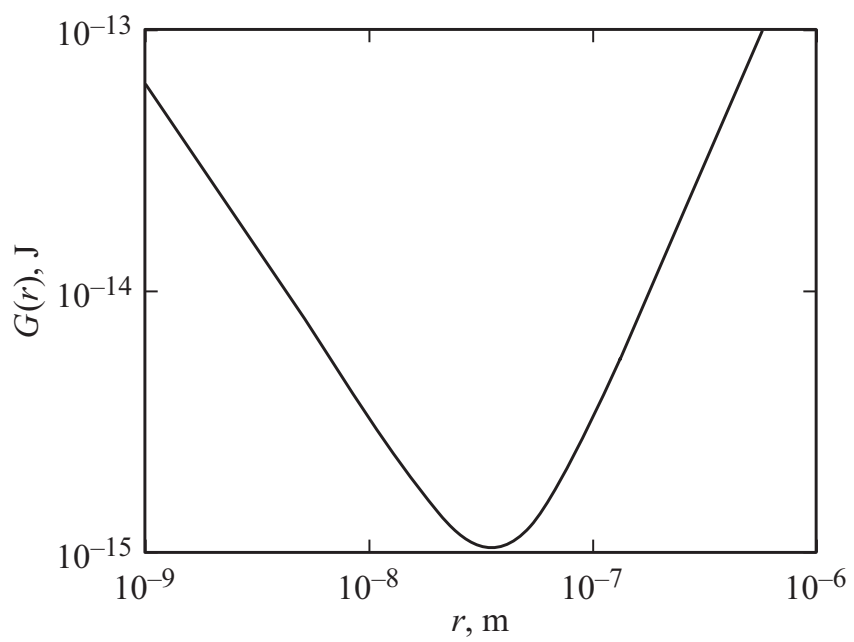

Рис. 1. Зависимость энергии Гиббса образования заряженного нанопузырька $G$ от его радиуса $r$. Расчетные данные: $c=10 \mathrm{~mol} / \mathrm{m}^{3}, T=273 \mathrm{~K}, z=1, \alpha=0.072 \mathrm{~J} / \mathrm{m}^{2}$. 


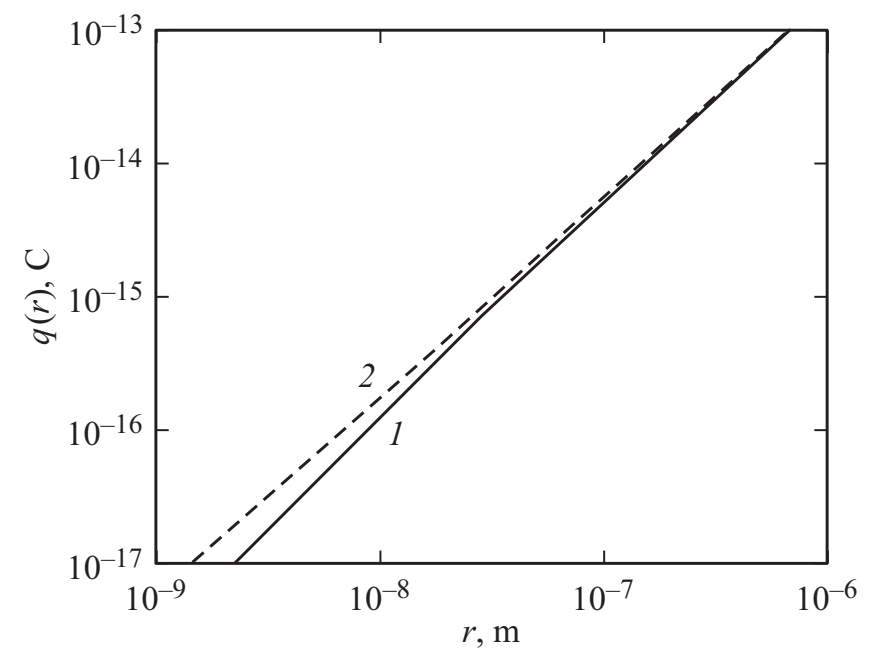

Рис. 2. Зависимости величины заряда стационарного $q_{s t}(1)$ и равновесного $q_{e q}(2)$ нанопузыря от его радиуса. Расчетные данные (значения $c, T, z, \alpha)$ те же, что для рис. 1.

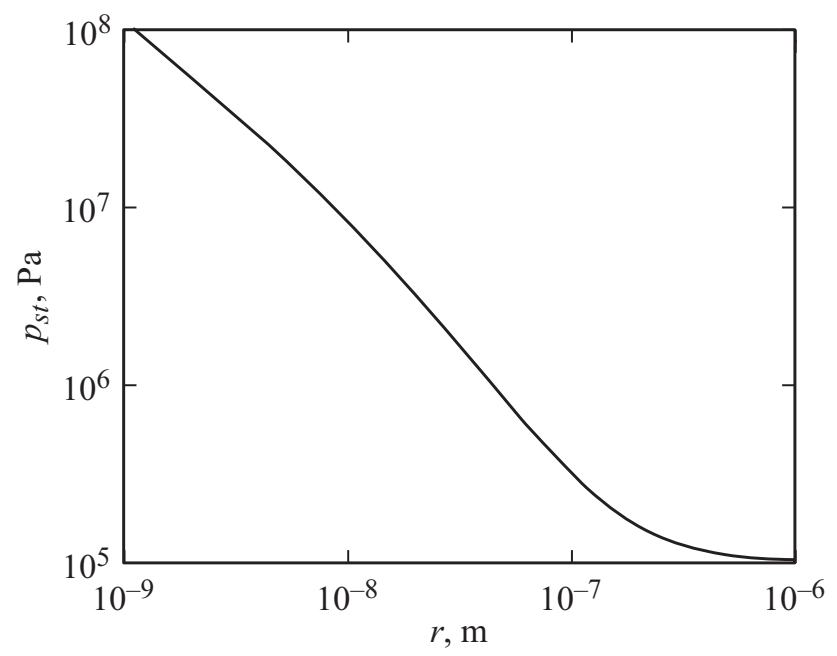

Pис. 3. Зависимость давления $p_{s t}$ в стационарном нанопузыре от его радиуса $r$. Расчетные данные те же, что для рис. 1.

$q_{e q}(r)=\sqrt{64 \pi^{2} \alpha \varepsilon \varepsilon_{0} r^{3}}$. Зависимости величин заряда стационарного и равновесного НП от его радиуса приведены на рис. 2.

Из проведенного анализа следует, что в результате гомогенной генерации формируется стационарный НП в соответствии с минимумом энергии Гиббса. Однако давление стационарного НП больше, чем у равновесного. Поэтому часть газа из НП переходит в окружающую среду, снижая давление газа в нем до $1 \mathrm{~atm}$, т.е. до равновесного (по закону Генри) с концентрацией молекул газа в водной среде. При этом заряд НП сохраняется, а радиус уменьшается до соответствующего значения, так что точка состояния нанопузыря на рис. 2 горизонтально переместится со стационарной кривой $q_{s t}(r)$ на равновесную $q_{e q}(r)$.
С помощью подстановки $q_{s t}(r)$ в (2) определим давление в стационарном НП

$$
p_{s t}=6 \alpha L_{D}\left(2 r+L_{D}\right) / r\left[\left(r+L_{D}\right)^{2}+3 L_{D}\left(2 r+L_{D}\right)\right]+p_{0} .
$$

Зависимость давления в стационарном НП от его радиуса представлена на рис. 3. Отметим, что кривая зависимости давления $p_{e q}$ в равновесном нанопузыре от его радиуса $r$ совпадает с осью абсцисс, поскольку в равновесном пузыре независимо от его радиуса давление равно атмосферному $p_{0}$.

Из рис. 3 следует, что величина давления в стационарном НП всегда больше атмосферного $p_{s t}>p_{0}$ и в рассматриваемом обычно в литературе диапазоне размеров НП $r=30-150 \mathrm{~nm}$ может изменяться от десятков до единиц atm. Соответственно количество $n_{s t}(r)$ молекул газа в таком нанопузыре равно $10^{4}-10^{5}$, что представляется достаточным для применения статистической термодинамики.

Итак, теоретически обоснована возможность самопроизвольной генерации наноразмерных пузырей в воде и предложен механизм формирования системы нанопузырей в водной среде: часть растворенных молекул газа формирует стационарные нанопузыри, уменьшая энергию Гиббса дисперсной газожидкостной системы. Затем давление газа внутри нанопузыря, изначально большее атмосферного, постепенно уменьшается до $1 \mathrm{~atm}$, переходя в равновесное (по Генри) состояние с окружающей водной средой.

\section{Список литературы}

[1] Бункин Н.Ф., Бункин Ф.В. // УФН. 2016. Т. 186. № 9. C. 933-952.

[2] Chaplin M. Water structure and science. www1.1sbu.ac.uk/ water/water_structure_science.html

[3] Koshoridze S.I., Levin Yu.K. // Nanosci. Technol. Int. J. 2018. V. 9. N 1. P. 1-8. DOI: 10.1615/NanoSciTechnol IntJ.2018 025819

[4] Liu Y., Zhang X. // Chin. Phys. B. 2018. V. 27. N 1. P. 014401. DOI: $10.1088 / 1674-1056 / 27 / 1 / 014401$ 